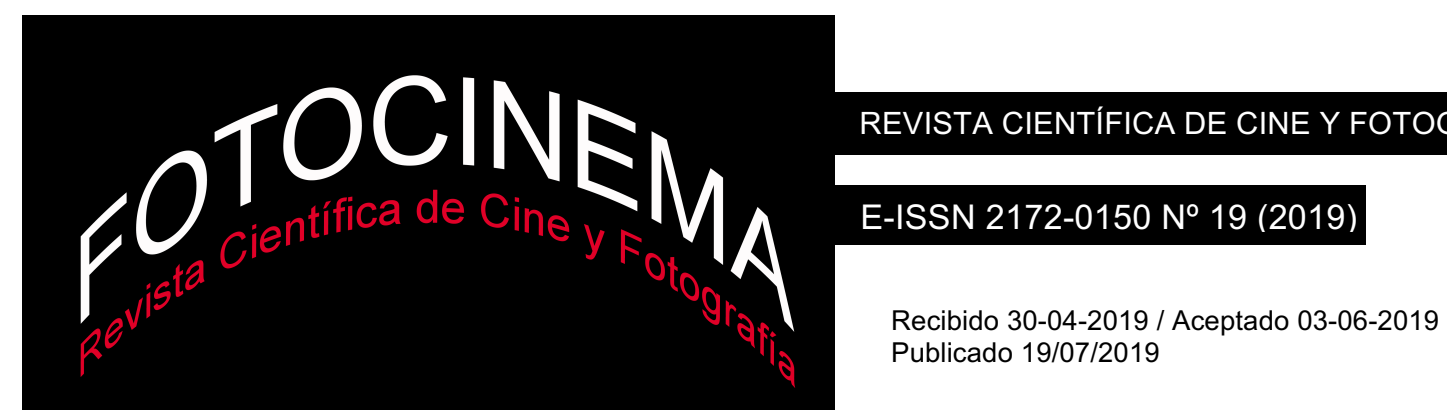

\title{
Oscuridad, una estrategia fotográfica en el límite de su esencia para representar la periferia urbana
}

\section{Darkness, a photographic strategy in the limit of its essence to represent the urban periphery}

\author{
Gema Pastor Andrés \\ Universidad Rey Juan Carlos \\ gema.pastor@urjc.es
}

\section{Resumen}

El paisaje urbano del cambio de siglo ha sido el tema predilecto de la fotografía artística de su tiempo. Su atención nos propone la reinvención personal y pública de los lugares comunes, pero además desentraña la esencia de las representaciones que lo dibujan.

Este artículo analiza fotografías de lugares en la periferia nocturna de la ciudad, lugares que pasan desapercibidos pero que, sin embargo, han recibido la mirada minuciosa de los artistas. Su interés revela tanto el complejo juego de realidad y representación que es cada fotografía, como la reflexión e intervención política posible sobre esa realidad. Para comprender estas imágenes utilizamos una metodología basada en la definición de paisaje.

Al profundizar en ellas descubriremos que tanto el paisaje como la fotografía lleva al extremo su esencia ontológica para zarandear los cimientos sobre los que se piensan, representan y ocupan esos lugares y esas representaciones.

\section{Abstract}

The urban landscape at the change of the century has been the favorite theme of contemporary artistic photography. This focus suggests a personal and public reinvention of common places, and uncovers the essence of these representations.

This paper analyzes photographs of places in the periphery of the city at night. Places which go unnoticed but that have received the detailed observation of the artists. Their attention reveals the complex relationship between both reality and representation in every photograph, as well as reflection and potential political intervention in this reality. To understand the images we used a methodology based on the definition of landscape.

As we go deeper into the images we discover the landscape and the photograph pushing their ontological essence to the limit. This shakes up the foundations of how we think about, represent and occupy these places and these representations.

\section{Palabras clave:}

Paradojas; Noche; Ciudad; Afueras; Espacio Público; Paisaje.

\section{Keywords:}

Paradoxes; Night; City; Outskirts; Public Space; Landscape.

La autora, Gema Pastor Andrés, quiere agradecer a los artistas y las galerías la generosidad y disposición para la publicación de sus obras en este artículo: Galería Gagosian de Nueva York, Galería Kow de Berlín, Galería Oliva Arauna de Madrid, Jeff Wall, Ralf Peters, Tobias Zielony y Studio Gabriele Basilico. 


\section{Introducción}

El proceso de ver el mundo está determinado biológica, fisiológica y culturalmente y también técnicamente. La fotografía como imagen técnica es una herramienta de exploración del mundo y de las ideas que lo dibujan. Las imágenes de la noche urbana de estos artistas nos invitan a mirar más intensamente, no a ver mejor, sino mirar más dentro de las representaciones y fuera del cuadro.

El cuerpo y el territorio, los conflictos y los procesos de pacificación, en su dimensión social y psíquica, son, actualmente y más que nunca, los polos de un programa de reinvención de los lugares comunes de la 'pintura de la vida moderna'. (Chevrier, 2007, p. 342)

Este texto trata de observar la fotografía artística de finales del siglo XX y principios del XXI que ha retratado el entorno urbano invisible y nocturno de las afueras de las ciudades para descubrir lo que nos propone sobre él.

Los objetivos del análisis son:

- Vislumbrar cuál es la propuesta de la fotografía contemporánea sobre los lugares comunes y la posible intervención política sobre esa realidad.

- Entender la periferia nocturna urbana a través de las imágenes.

- Descubrir las estrategias fotográficas que utilizan los artistas para comunicar sus inquietudes sobre esos lugares.

El texto comienza definiendo primero qué es el lugar, el entorno propio, estudiado por las ciencias sociales. Es el entorno psicológico y social con los otros: de relación, de interacción, de apropiación, de identidad y de vivencia. Este marco teórico define el referente de las imágenes que vamos a analizar, lo que hay representado. Para ello se han seleccionado 4 imágenes que se leerán en dos pares. Estas imágenes han sido elegidas de una base de datos de 5000 imágenes porque retratan una forma paradigmática de paisaje contemporáneo en un momento de poca visibilidad: el extrarradio de la ciudad en la noche. En las afueras se manifiestan las formas más puras del paisaje urbano contemporáneo estandarizado a lo largo del mundo. "En la periferia es allá donde la pérdida de identidad $\mathrm{y}$, por tanto, la 
desconstrucción del concepto de lugar resulta más patente” (Esparza, 2002, p. 140).

Para leer cada par de imágenes proponemos una metodología basada en la definición propia de paisaje (Pastor Andrés, 2016), ese entorno sensible que desde la filosofía y la estética estudia la relación de los seres humanos con el entorno representado. Como explica Pierre Francastel en La figura y el lugar (1988) las artes figurativas, y el paisaje por definición es uno de sus géneros más importantes, no sólo representan el mundo sensible, sino que denotan las relaciones entre lo percibido, lo real y lo imaginario, como ninguna otra forma de expresión humana ha sido capaz de hacerlo.

\section{Conceptualización}

\subsection{El lugar, el referente}

La relación con el lugar dibuja cómo es el entorno psicológica y socialmente con los otros. "El lugar es expresión de la sociedad y las prácticas en él lo definirán: es la sociedad misma” (Castells, 2001, p. 488). La relación directa con el entorno queda reflejada en los lugares: desde nuestro refugio -el

hogar- hasta nuestro entorno público más inmediato -nuestro pueblo o nuestro barrio.

Los estudios que han abarcado las relaciones de los habitantes del lugar se engloban en las ciencias sociales y definen el lugar desde paradigmas culturales (proxémica), vitales (psicología del espacio) y sociales (teorías de apropiación del entorno).

Los primeros aportes de la proxémica explican cómo la construcción social del entorno, desde distintas esferas (íntima, personal, social y pública), está determinada por la cultura, y cómo esta influye en la percepción del mundo y la construcción de los lugares. Es decir, "sirve para entender el espacio personal y social y la percepción que el hombre tiene de él” (Hall, 1972, p. 6).

La psicología del espacio, desde los primeros estudios de Abraham Moles en los años 6o, se ha interesado por el individuo que tiene una relación con el 
entorno, no legalmente, sino desde una aptitud con respecto a él, que puede ir cambiando y evolucionando a lo largo de su vida (Vidal y Pol, 2005, p. 283).

Las recientes teorías sobre la apropiación del entorno relacionan los vínculos que se generan entre las personas y sus entornos, es decir cómo se construyen socialmente los lugares (Berroeta \& Vidal, 2012). El lugar es aquel con el que se produce una relación de identidad (del individuo y de los grupos que lo viven), se crean unos vínculos y se desarrolla una relación de afecto y apego. Lo que define, entonces, cualquier lugar es cómo el ser humano se aferra a él, se lo apropia. La apropiación del entorno a la que se refiere el lugar tiene que ver con un asentamiento mental en el mismo que construye a quienes lo habitan, y con el que se siente una relación directa: estoy aquí y me hago cargo de mis actos en el lugar, y lo aprecio y siento cercano.

Dos son los lugares por antonomasia sobre los que se asientan cultural, vital y socialmente los seres humanos, la casa (como hogar y refugio) y el espacio público (de interacción con los otros).

\subsubsection{La casa}

El primer lugar de referencia es la casa, lo explica muy bien García Márquez al comienzo de su autobiografía, es nuestro rincón en el mundo.

- Vengo a pedirte el favor de que me acompañes a vender la casa.

No tuvo que decirme cuál, ni dónde, porque para nosotros sólo existía una en el mundo: la vieja casa de los abuelos en Aracataca, donde tuve la buena suerte de nacer y donde no volví a vivir después de los ocho años (García Márquez 2003, p. 10).

Es "nuestro primer universo (...) Sin ella el hombre sería un ser disperso. Lo sostiene a través de las tormentas del cielo y de las tormentas de la vida” (Bachelard, 2004, p. 34-37).

El hogar se refiere a la necesidad de apropiación de un bien primario referencial: el refugio. "La casa es un cuerpo de imágenes que dan al hombre razones o ilusiones de estabilidad" (Bachelard, 2004, p. 48). La casa es el 
lugar sobre el que se ejerce una propiedad legal y en el que se tiene la referencia geográfica primaria. Es el entorno íntimo que gestionamos directamente y que por lo tanto refleja nuestros modos de vida y nuestra personalidad.

\subsubsection{El espacio público}

El siguiente lugar de referencia es el 'espacio público'. Éste funciona como una prolongación de 'la casa'.

Los recientes estudios sobre la apropiación (Vidal y Pol, 2005) desmenuzan el proceso por el cual un 'espacio público' se convierte en lugar, en entorno propio. Este proceso supone para la persona o el grupo la accióntrasformación del espacio público y la identificación simbólica con él. Con la acción-transformación el ser humano deja su huella sobre el entorno, lo incorpora a su forma de entender y conocer el mundo y genera con él vínculos de reconocimiento y afecto: lo aprecia. Por medio de la identificación simbólica el individuo o el grupo puede reconocerse, haciendo que las cualidades del lugar se conviertan en definitorias de su propia identidad. Su imagen del mundo está unida a la imagen de ese lugar: se refiere al lugar a menudo, el nombre del lugar funciona como una referencia semiológica, es la fuente de percepciones estéticas (bellas o no), etc.

\subsubsection{La disolución del espacio público}

Los espacios públicos, como lugar del cual poder apropiarse y generar sociedad, se diluyen en entornos donde se priorizan otras actividades: consumo, entretenimiento, ocio, etc. El proceso de globalización económica imperante a finales del siglo XX y principios del XXI produce una ocupación de lo 'público' por asuntos privados (Sennett, 2001, Bauman, 1999). Para Trevor Boddy (2004), la ciudad se ha convertido en un simulacro que ha descuidado la 'civitas' y la 'polis'. Augé (2000) ha inventado el término no lugar para definir los entornos en los que no se produce ningún intercambio, ni entre las personas, ni entre estas y el entorno. Castells (1998) propone una doble lógica para el espacio: frente al espacio tradicional de los lugares espacio de interacción social-, ha surgido el espacio de los flujos que 
concentra el poder, la riqueza y la información. Berroeta y Vidal nos previenen de lo que esta disolución esconde:

Si se consideran las funciones sociales y las capacidades reales que tiene todo proyecto urbano, las consecuencias para la construcción de ciudad de esta indiferenciación son particularmente paradójicas y amenazantes. Los gestores urbanos se amparan en este relato superficial de civilidad y democracia para justificar sus intervenciones privatizadoras y coercitivas, obviando el sustrato ideológico-normativo del espacio público (2012, p. 47).

¿Cómo nos relacionamos en este nuevo espacio-tiempo en el que aparentemente han desaparecido las distancias, donde lo global está a la vuelta de la esquina y lo local se ha vuelto lejano?, ¿es cierto que cualquiera puede hacer suyo el mundo entero como lugar para la vida?, ¿es verdad que la libertad de acción es mayor y que son tangibles más posibilidades o hemos perdido la posibilidad de construir el mundo junto a aquellos que nos rodean...?

\section{Metodología, sobre la representación del lugar: paisaje}

El paisaje es el entorno sensible porque puede ser percibido por el sentido de la vista y produce sensaciones, tanto en su visión directa como en su representación.

$\mathrm{Su}$ apreciación y su representación se basan en la aprehensión de la distancia, tanto en el horizonte como en el lienzo: plasmar esa distancia constituirá la manera de dibujar los significantes sobre el plano del cuadro de la fotografía.

El modo en el que el entorno genera sensaciones, tanto a través de la vista como en la representación, define (siempre que sea eficaz el trabajo de los significantes) las sensaciones que ese paisaje provoca, y muestra cuales son los significados que nos transmite.

Para el análisis de las fotografías de los artistas aplicamos una metodología que surge a partir de esta definición de paisaje (Pastor Andrés, 2016, 110113). Este modelo metodológico, abierto y atento a la visión de las fotografías, 
de lectura observa: en primer lugar cómo los significantes representan la distancia (con relación a lo que se ve, a lo que se sabe -iconografía- y a lo que se explica con el título, el statement del artista, etc.); y en segundo término los significados reflejo del entorno sensible en tres sustancias dentro del marco: el contexto (lo que se representa), la acción (el entorno interiorizado, la propuesta del artista) y la reacción posible en la representación, en lo representado (puesto que ésta provoca sensaciones en el espectador).

\section{Periferias en la noche, análisis}

Los tempos y los modos de nuestra acción están predeterminados por la luz que los alumbre. Durante el día, o con la luz artificial del centro, la actividad es frenética y urbana, pero fuera de ese entorno lo 'poco' que pasa queda en las sombras. Qué ocurre si no pertenecemos a ese entorno vivo y luminoso, John Berger nos propone colocarnos en el lugar de los que viven en ella:

Sólo alguien que haya vivido en las calles de una ciudad, soportando algún tipo de miseria, puede darse realmente cuenta de lo que significan los adoquines, los portales de las casas, los ladrillos, las ventanas. A un nivel callejero, fuera de los vehículos, todas las ciudades modernas son violentas y trágicas. La violencia de la que tanto hablan los informes policiales y los medios de comunicación es, en parte, un reflejo de esa otra violencia que, con ser más antigua y más continua, no parece preocupar a nadie (2006, p. 99).

Si además de estar en la calle, fuera de la casa o del coche (sin una carcasa que nos proteja), es de noche, estamos doblemente indefensos: la oscuridad no nos permitirá percibir lo que tenemos alrededor. Fuera, a un nivel callejero, en la oscuridad de la noche, estamos al otro lado de la pared que hemos construido para resguardarnos, no sólo físicamente, sino mental, psicológica y socialmente: no estamos en el interior de nuestro luminoso y cálido hogar o coche.

Lo que normalmente se hace o puede hacerse en un determinado espacio público es lo que le define, lo demás está fuera de lo normal en ese lugar. ¿Cómo una costumbre puede convertirse en norma?, ¿cómo se pueden 
cambiar las normas?, ¿cómo rompen las normas para generar unas nuevas? Según comenta Jordi Borja en su propuesta de Nuevos derechos ciudadanos como respuesta política a los nuevos desafíos del territorio, los derechos de la ciudadanía deberían ampliarse incluso para dar cabida a posturas fuera de la ley.

Derecho a la ilegalidad: paradójicamente tanto los colectivos sociales, como a veces, las instituciones locales deberían asumir el coste de promover iniciativas ilegales o alegales para convertir una demanda no reconocida en un derecho legal (Borja, 200o, p. 13).

\subsection{Luz azul}

¿Qué se puede o no hacer en una gasolinera de noche? Fijémonos en la foto Aral Station-1-40o (2004) de Tobias Zielony (1973) dentro de su trabajo Tankstelle sobre gasolineras en Alemania (F1). En la imagen vemos iluminada una gasolinera en medio de la noche profunda. Debajo de la marquesina de la estación hay varios coches parados y, entre un par de ellos, un grupo de personas, sin llenar los depósitos de gasolina, parecen estar conversando.

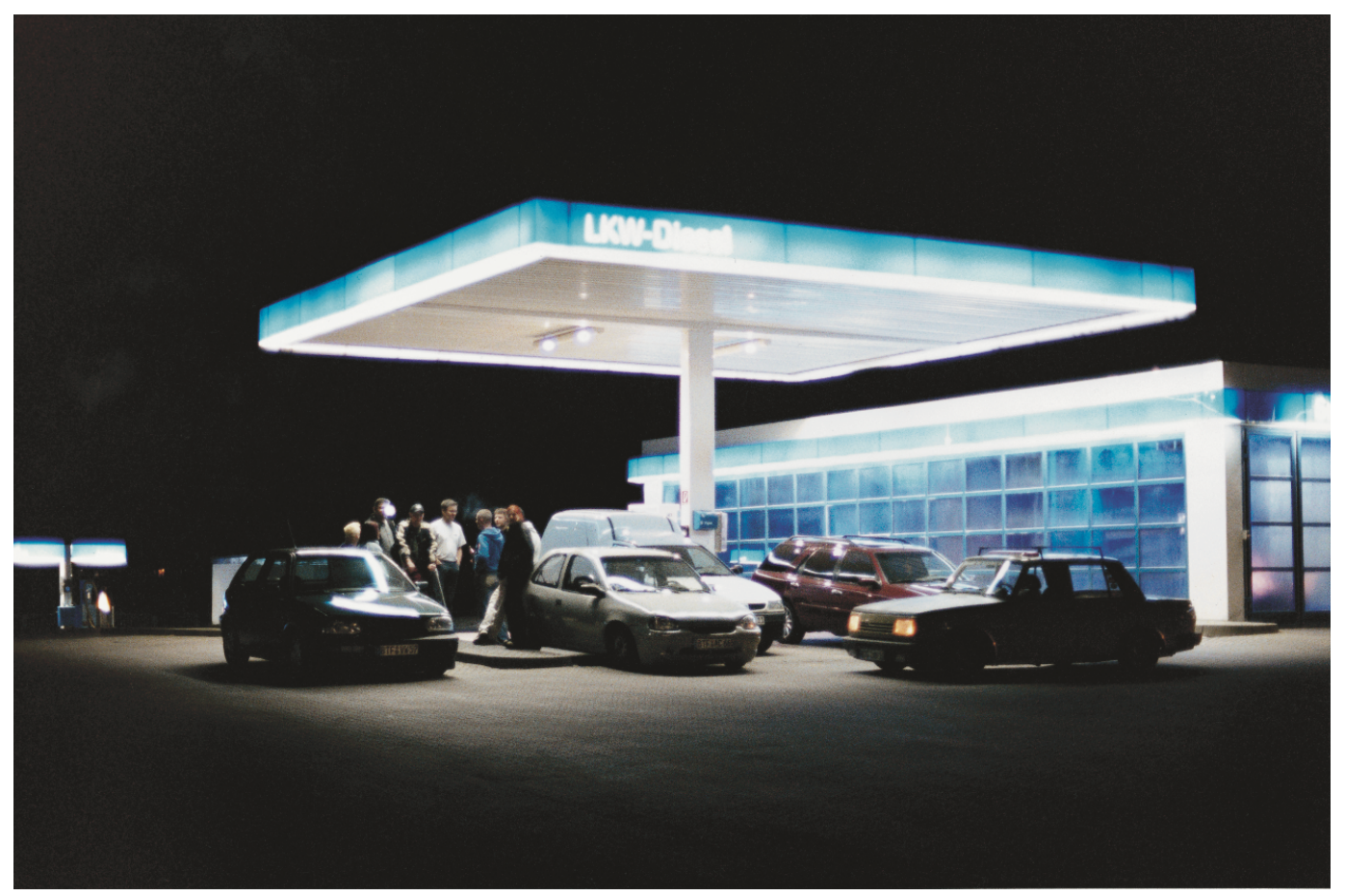

F1. Tobias Zielony, Aral Station-1-400, 2004, (C) Tobias Zielony. Cortesía del artista. 
El artista Ralf Peters (1960) en offen-open Tankstelle weiss - blau de la serie Tankstelle 1998 (gasolineras) retrata también las luces de una estación de servicio de Alemania en medio de una noche cerrada. En este caso no hay nada ni nadie, sólo la luz de neón azulada del exterior y el interior de la tienda iluminado nos descubren que hay vida (F2).

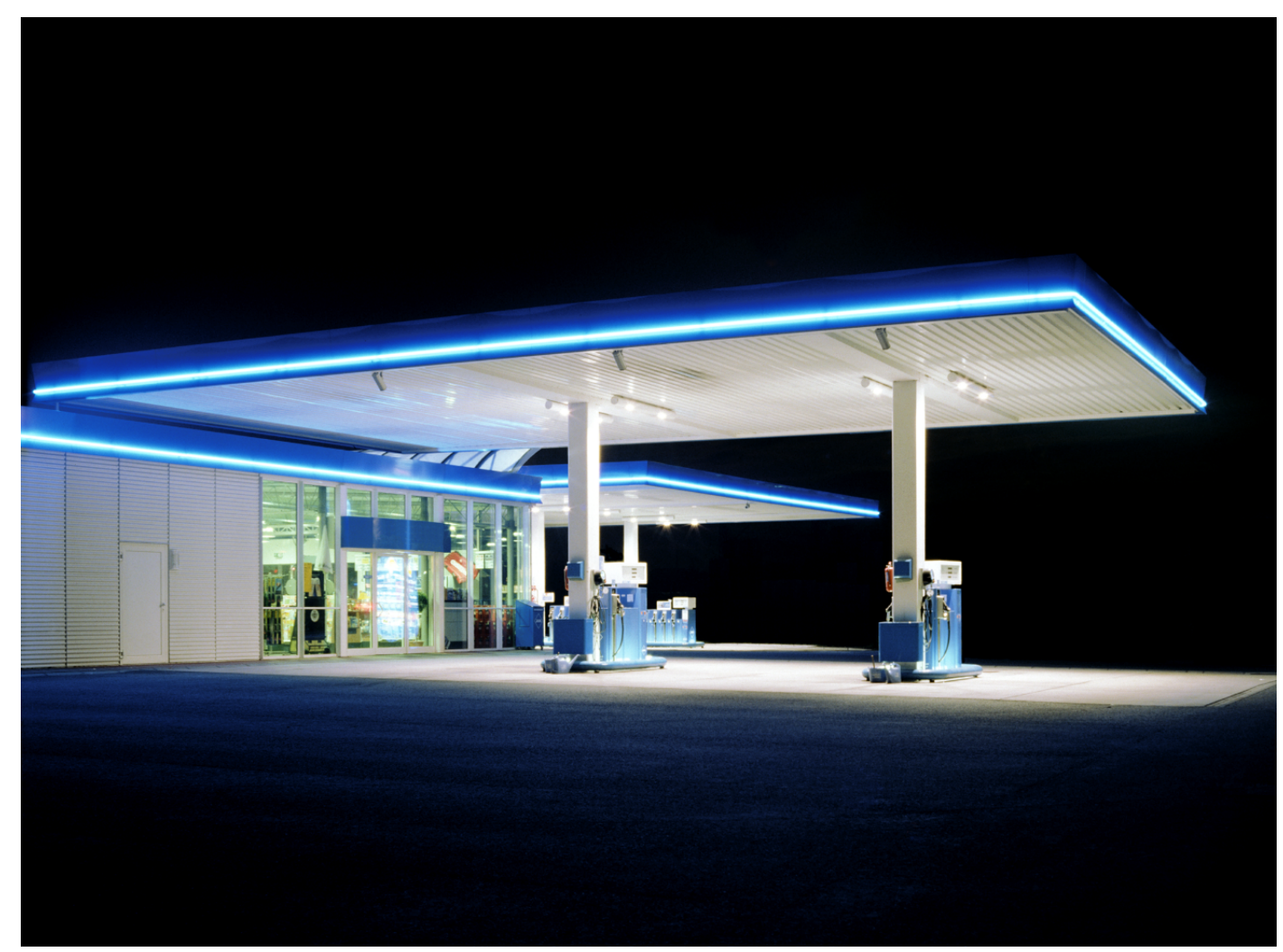

F2. Ralf Peters, offen-open Tankstelle weiss - blau de la serie Tankstelle 1998. C Ralf Peters. Cortesía del artista.

El entorno que nos muestran las dos fotografías a análisis es el mismo a la misma hora: lo podemos apreciar en la composición, la luz y el color de ambas imágenes. La noche es oscura, y no vemos nada que no sea el entorno inmediato que ilumina la gasolinera, levitando en la negrura: el sándwich azulado entre la marquesina y el suelo nos muestra los detalles, fuera de ese entorno no queda más suelo donde apoyarnos. La única luz en la noche donde refugiarnos, y a la que sólo podemos llegar en coche.

Ambos trabajos recuerdan la publicación de 1962 Twentysix gasoline stations del pintor americano Edward Ruscha en la que recopila 26 fotografías de gasolineras de Estados Unidos. La indiferencia ante el objeto 
elegido removió los cimientos de la fotografía hasta el momento. La estética de carretera refleja una mirada distanciada e irónica.

Pero la similitud sólo es temática. La publicación de Ruscha denota una falta de preocupación por la toma, el encuadre, la obturación, el momento o la luz, y elige la banal gasolinera para una obra conceptual, en un ejercicio de apropiación, descontextualización y negación del trabajo artesano del artista.

Sin embargo, las fotografías sobre gasolineras que estamos analizando muestran mucho interés por el objeto retratado, la reflexión sobre su estética $\mathrm{y}$ funcionalidad es fundamental en ambas obras, a pesar de que los caminos para llegar a ella sean distintos.

El trabajo de Ralf Peters tiene reminiscencias de las metódicas repeticiones de la obra de Ruscha, pero sobre todo recuerda las sistemáticas tomas del matrimonio Bern y Hilla Becher por la repetición del encuadre, la posición de la toma, el tratamiento de la luz, el color y la textura, en todas y cada una de las imágenes.

El trabajo de Tobias Zielony sin embargo tiene más que ver con el trabajo periodístico que evoca un humanismo interesado en el documento social. El tríptico recuerda el trabajo de reportaje en el que los distintos puntos de vista aportan información sobre el tema.

Las dos fotografías nos colocan delante de una gasolinera azul en medio de la noche, en el mismo país: Alemania, y sin embargo la acción que nos cuentan las imágenes, su historia, es completamente distinta. El contexto es el mismo, lo que quieren contarnos los fotógrafos no.

El tríptico de Aral Station-1-40o de Tobias Zielony nos muestra es un grupo de jóvenes que se ha reunido en la gasolinera:

En las periferias europeas -siguiendo un fenómeno nacido en Estados Unidos- la falta de lugares de encuentro ha obligado a los jóvenes a adoptar 'no-lugares', espacios anónimos y estandarizados, y a transformarlos en espacios de socialización (Zielony 2005). 
Las imágenes nos descubren una acción en un solo entorno desde distintos puntos de vista: el encuentro de un grupo de jóvenes en una gasolinera: qué hacen, cómo charlan, cómo se relacionan.

En cambio, en las fotografías de la serie de Ralf Peters lo que se repite es el punto de vista y tipo de plano elegido para mirar de manera sistemática distintas gasolineras. Estamos colocados en el acceso que nos lleva a cada una de ellas. Desde fuera, las podemos observar de manera general, y a pesar de cambiar de gasolinera parece que siempre estamos en la misma que sólo cambia de color: verde-blanco, morado o rojo. La homogeneidad de este tipo de construcciones contemporáneas se hace todavía más patente retocando digitalmente las imágenes para eliminar toda la parte gráfica que las identificaría.

Si Ralf Peters nos coloca fuera y a la misma distancia en múltiples gasolineras que parecen la misma, a Tobias Zielony sólo le acompañamos al interior de una: nos permite acercarnos y alejarnos al grupo de jóvenes que hablan entre los surtidores. Estamos con ellos: llegando, detrás o al lado; las distintas tomas nos indican que somos uno más de los que han quedado allí, estamos dentro del grupo.

En medio de la noche, no hay ningún otro lugar 'civilizado' más allá del establecimiento, ni siquiera hay suelo para sostenernos. ¿Por qué los fotógrafos nos proponen esa hora del día? Estos establecimientos son de los pocos espacios públicos que no tienen restringido su horario ni en días ni en horas del día: abierto 24 horas, lo que permite observarlos como una isla de luz en la noche. Son un refugio donde hay luz, avituallamiento y víveres en medio de la oscuridad.

\subsubsection{No lugar}

Las fotografías de la serie de Ralf Peters nos muestran el 'no lugar' el lugar de paso: estamos en la carretera dentro de un coche y, entrando o saliendo de la carretera, a través de las ventanillas vemos un entorno vacío.

Las fotografías del tríptico Aral Station-1-40o de Tobias Zielony nos enseñan un lugar ocupado, el lugar de paso, el 'no lugar' se ha convertido en lugar, la 
ocupación temporal que los jóvenes hacen transforma la función y la esencia del entorno:

Las arquitecturas urbanas sin un usuario definido son colonizadas, y el uso para el que fueron proyectadas se convierte en el trasfondo de nuevas relaciones. Estas 'invasiones' periódicas demuestran hasta qué punto el carácter definido de un lugar puede ser subvertido por la iniciativa de individuos o grupos capaces de interpretar el espacio urbano. Los nuevos lugares de encuentro son las áreas de servicio, los aparcamientos de centros comerciales, las zonas comunes de grandes complejos arquitectónicos o las estaciones de autobuses (Zielony 2005).

¿Por qué los jóvenes eligen esos entornos para encontrarse? Son espacios públicos que están abiertos hasta muy tarde o incluso toda la noche, están cerca de su residencia en el extrarradio de las ciudades, pero sobre todo hasta allí pueden llegar en su única propiedad: el coche. La falta de poder adquisitivo, suficiente para poder emanciparse (comprar una casa es difícil para muchos de ellos), sí les permite tener una única propiedad independiente del resto de la familia: el coche como inversión y referencia de identidad. Es su casa a cuestas, como la del caracol que se mueve con ella.

Las sensaciones que la gasolinera puede producir son distintas: las reflexiones van desde el poder de su imagen a la acción posible en su interior. No sabemos el lugar exacto en el que estamos, pero nos sentimos protegidos bajo su tejado horizontal y luminoso, en un sándwich de luz blanco y azul. Es cualquier lugar porque no hay nada que lo distinga e identifique (si estamos al tanto de que estamos en Alemania es porque nos lo han dicho sus autores). Las gasolineras se han convertido en lugares homogéneos, iguales a lo largo de las carreteras del mundo, y son tan genéricas y globales que es imposible diferenciarlas a no ser que conociéramos la distribución mundial de las marcas dispensadoras de gasolina. Lo cierto es que ambas están preocupadas por la estandarización del espacio público y surgen como reacciones: a través de la 'cultura' que borra el texto o la 'contracultura' que ocupa el espacio.

Ralf Peters propone una reacción pasiva, una reflexión sobre el poder y la imposición de un tipo determinado de imagen en detrimento de la variedad. 
En ese espacio 'no lugar', en el que parece que nunca pasa nada, la luz de colores revela el poder de la superficie del entorno comercial limpio y de líneas rectas. La imagen pura y similar a lo largo del mundo, como nos comenta Ahrens:

Estas fórmulas son, al igual que algunos signos de rígido secreto funcional, el reflejo del inquebrantable poder del mundo de los negocios. La apariencia de colorido si es soso elimina la diferencia que dirige nuestra mirada a la estética que nos saluda dondequiera que pisemos en una ciudad moderna. Aunque cegada por la brillante superficie de estas réplicas arquitectónicas, extraídas por estetización de su contexto comercial, nuestra percepción ofrece una forma profundamente crítica con el concepto de arquitectura (2001).

Tobias Zielony nos propone una reacción activa, nos enseña sin embargo una acción que se ha producido ya. La respuesta viva ha ocupado el 'no lugar' hasta transformarlo en lugar. El espacio público se apropia por una alternativa a su función estándar. La norma ha sido sustituida por el uso.

Las dos series de Tobias Zielony y Ralf Peters tienen una posición crítica con respecto a ese entorno, sólo es una cuestión de distancias, de estar o no dentro del cuadro. Las dos imágenes miran la gasolinera como 'no lugar' desde dos actitudes distintas, a través de la cultura y la contracultura. Uno 'rarificando' lo normal al despojarlo de sus elementos de identificación y haciendo si cabe más visibles los parámetros repetitivos que construyen todas las gasolineras. Otro ocupándolo con una acción 'rara' porque está fuera de lo normal.

\subsection{Gris oscuro}

Y más allá de esa luz, ¿qué se puede o no hacer en la periferia de la ciudad por la noche?

La fotografía en blanco y negro Milano (1995) de Gabriele Basilico (19442013) nos muestra el lateral de una calle con un muro, con una puerta cochera, y varios bloques de pisos detrás. Es de noche y el cielo está completamente negro. La calle está iluminada por una farola, que no vemos, situada al otro lado de la calle junto a nosotros. Los bloques, detrás del 
recinto cerrado por el muro, están iluminados por las farolas a sus pies de abajo a arriba. Todas las ventanas están a oscuras excepto una línea vertical en el bloque más cercano, como si alguien hubiera encendido la luz de las escaleras al llegar a casa o irse (F3).

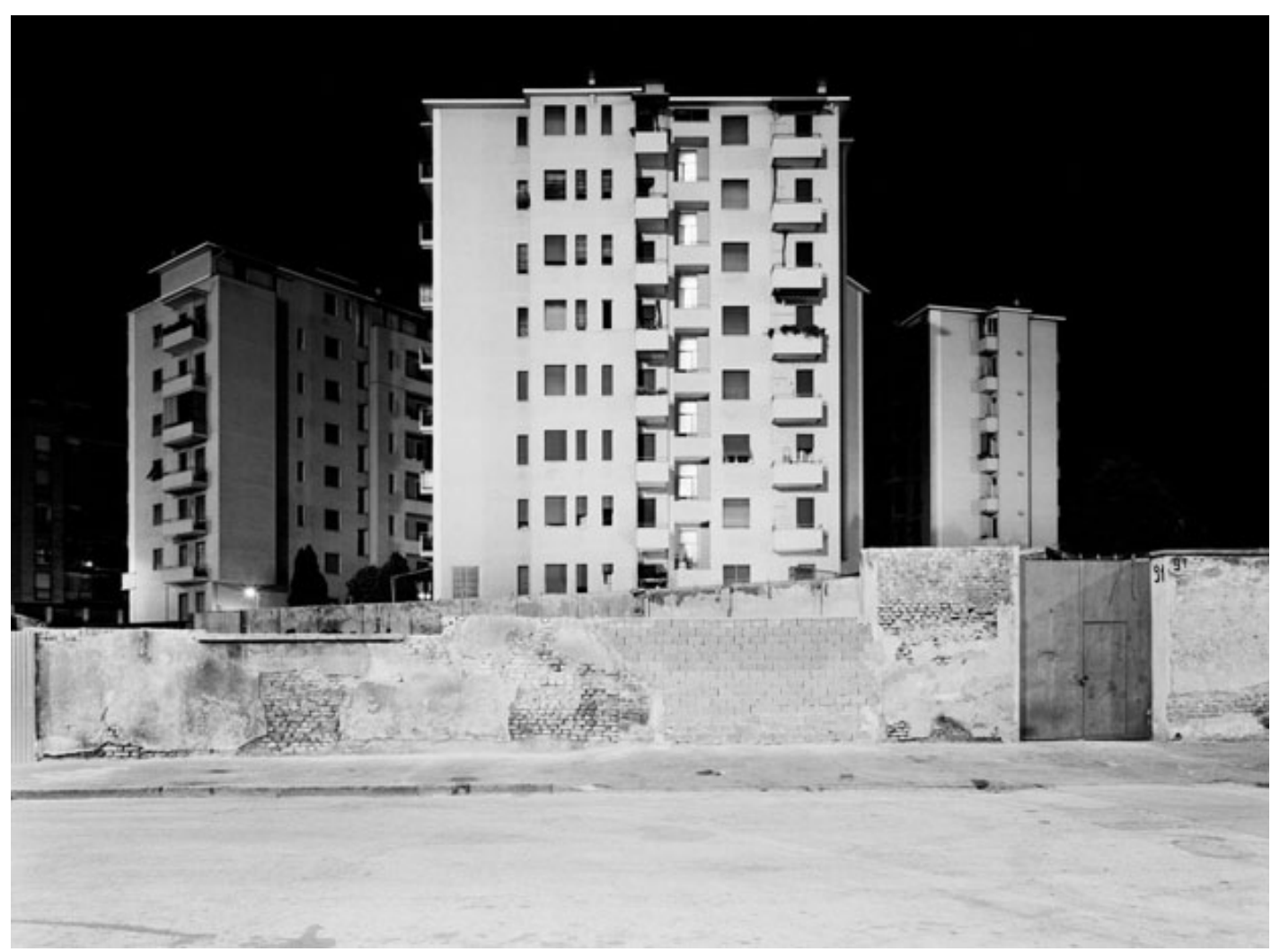

F3. Gabriele Basilico, Milano 1995. (C) Gabriele Basilico.

En la fotografía Night (2001) de Jeff Wall (1943), como su propio nombre indica, también es de noche, pero en este caso no hay ninguna farola que nos ilumine o enseñe los detalles de dónde nos encontramos, todo está sólo insinuado: la fotografía más que en blanco y negro es casi completamente negra. Vemos la orilla de cemento a la que llega el agua, y justo detrás los estribos de sujeción de un puente sobre el terraplén. Abajo, a la orilla del agua, no sabemos si es río, lago, mar o charco, hay una persona, parece una mujer, recostada en el suelo y rodeada de objetos $\left(\mathrm{F}_{4}\right)$.

En ambas fotografías nos encontramos en un entorno urbano donde domina el cemento, el asfalto y el hormigón, pero no las luces y los luminosos del centro de la ciudad, sino el gris monótono y oscuro de un lugar inespecífico, un lugar sin personalidad y sin luz que podríamos encontrar en la periferia 
de cualquier ciudad del mundo. Además, la noche, el momento elegido para mirarlo, otorga una intención reveladora a las fotografías: si normalmente no nos fijaríamos en ese entorno nocturno, sin luz, ni siquiera podríamos verlo, ¿por qué los fotógrafos quieren que nos fijemos en ese momento en ese lugar?, ¿’por qué lo retratan en blanco y negro?

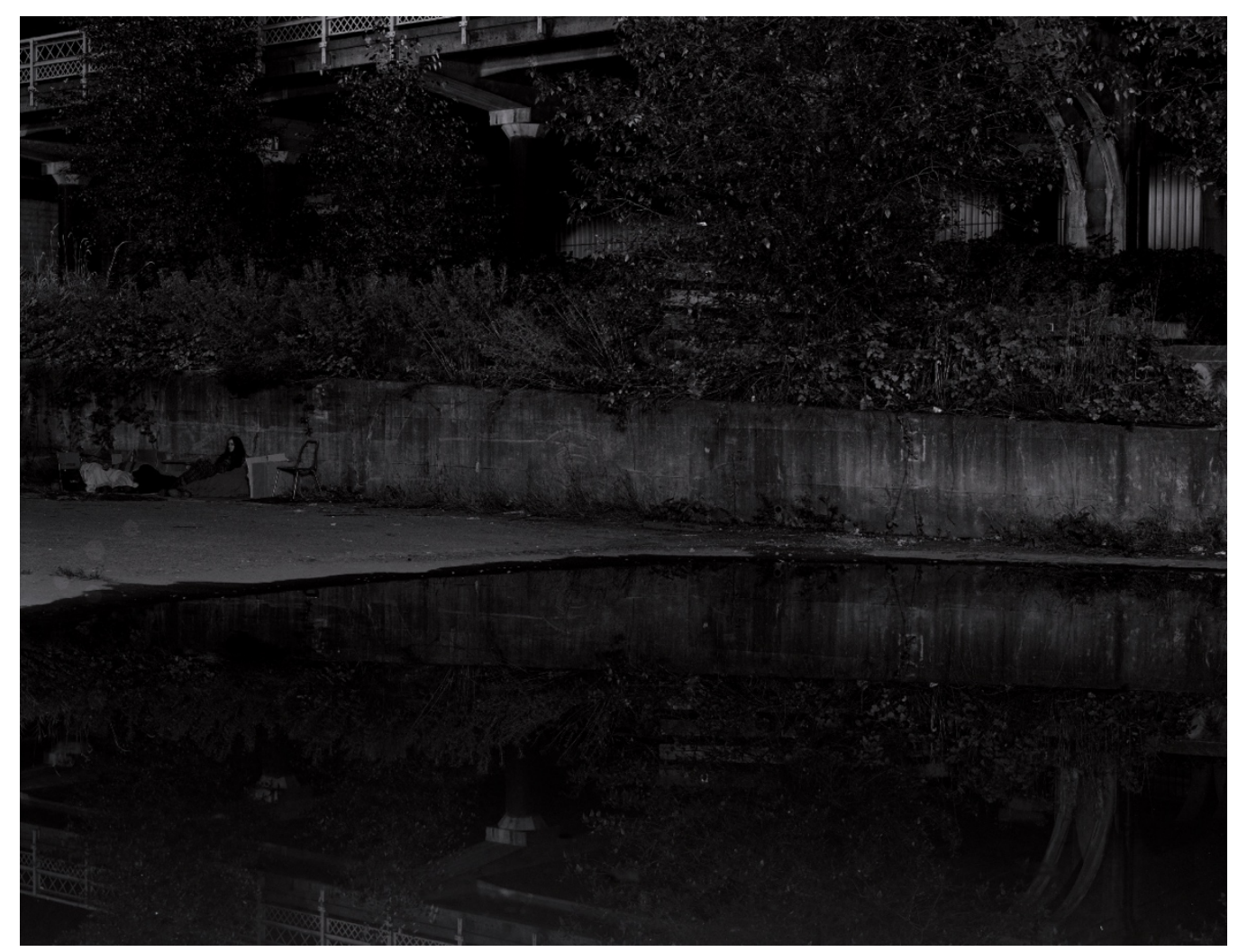

F4. Jeff Wall, Night 2001, silver gelatin print 238.8 x $301.6 \mathrm{~cm}$. (C) Jeff Wall. Cortesía del artista.

Es una imagen que no se ve, no porque no exista si no porque es difícil mirarla, hay que acostumbrar primero a la vista a esa falta de luz para poder empezar a fijarse en ella. Una vez que nuestras pupilas se hayan adaptado sólo distinguiremos los bultos de las figuras que nos rodean, pero no sus colores, la visión es parecida a una imagen en blanco y negro (en clave baja y con mucho ruido). Las fotografías Milano y Night nos proponen una vista similar a la que tenemos cuando hay muy poca luz y ya hemos pasado el suficiente tiempo en la oscuridad como para empezar a ver una imagen sin color, en blanco y negro. 
El blanco y negro en este caso permite engrisecer todo: volverlo del color del cemento para resaltar su textura inorgánica. En la fotografía de Wall hay una mancha arbórea entre el puente y la orilla del agua, pero la imagen la ha convertido en una mancha informe de un gris oscuro con una textura que no lo define. En ambas es el entorno urbano construido con moldes rellenos de polvo gris.

Además, la fotografía en blanco y negro, asociada al estilo documental, les permite examinar la autenticidad de la representación. El blanco y negro de las imágenes nos recuerda el perdido extrarradio que nos descubrió el cine del neorrealismo, tanto formalmente sobre todo en la imagen de Basilico como en la intención del movimiento cinematográfico: hacerlo visible.

Gabriele Basilico trabaja habitualmente en grandes formatos en blanco y negro con mucha nitidez para proporcionarnos una contemplación distinta a la que estamos habituados, una mirada más pausada de la realidad de la ciudad:

En una ciudad hay zonas diferentes por la historia, la tipología de los edificios, la composición social: la ciudad es sobre todo un lugar lleno de contradicciones que a menudo la fotografía, con su capacidad selectiva, tiende a separar y aislar. En mi proyecto visual pienso, sin embargo, que es constante la intención de buscar con la imagen un equilibrio, para restituir una coherencia que pueda amortiguar las tensiones y profundizar en la naturaleza del paisaje urbano, más allá de cada aspecto (Basilico en Fernández-Cid, 2008).

Jeff Wall en 1996, después de veinte años trabajando en sus grandes cajas de luz en color, vuelve a la fotografía en blanco y negro con Volunteer sin abandonar su personal estilo en el que el sentido cinematográfico de la escena pictórica de la fotografía juega con la representación documental de la realidad.

La falta de iluminación en ese entorno nos obliga a permanecer un momento mirando hasta adaptar nuestras pupilas. Al rato veremos en la imagen fija el paso del tiempo en el que no pasa nada: el silencio y la quietud envuelven el ambiente. La fotografía en este caso no detiene la calma en un instante, sino 
que la condensa: a pesar de que no hay movimiento todo parece detenido, retardado. No asistimos al instante determinante de la fotografía, sino que somos espectadores de la densidad resultante de la acumulación temporal en una sola imagen, el tiempo ha sido reconcentrado en el instante de la toma. Las dos fotografías se comportan como instantes sucesivos de una larga noche.

La noche, la falta de iluminación y la clave baja, junto con la pesadez del tiempo, el blanco y negro, la frialdad de la representación y el juego con la legitimidad de la documentación de la realidad, dibujan el contexto propicio para un suceso indeterminado. La textura psicológica de las fotografías proyecta un momento de incertidumbre justo anterior a una acción incierta.

En otras fotografías ampliamente conocidas, en blanco y negro y también nocturnas sucede todo lo contrario, son las imágenes de Weegge: el ambiente cargado tras una acción grave se sigue manteniendo en el espíritu de la fotografía en el momento de la toma, y la pregunta que nos hacemos observándolas es ¿qué ha pasado?

En las fotografías Milano y Night la pregunta es ¿qué va a pasar? Porque sentimos que la densidad resultante de la acumulación temporal nos incomoda, que ese impase terminará con algún suceso. Una pregunta todavía más desasosegante que el hecho consumado que retrata Weegee. Para conseguir estas sensaciones ambos fotógrafos estudian el entorno urbano que les rodea. Jeff Wall recopila información y recrea la escena como si de una película se tratara, con iluminación, actores, etc. Gabriele Basilico escoge minuciosamente el encuadre, el momento de la toma y el vacío de la arquitectura. El primero se centra en la gente en la calle, el segundo en la arquitectura para esa gente, pero ambos están pendientes de ese entorno inhóspito e inespecífico que forma una parte muy importante de la ciudad actual en la que vivimos y que no vemos.

Jeff Wall y Gabriele Basilico fotografían la noche en blanco y negro para hacerla menos brillante, más opaca. Ambos proponen una mirada detenida, pausada y reflexiva sobre la realidad inmediata, ni mediática, ni espectacular. 
La búsqueda de la representación de una belleza más pura, aquella no bonita, que revela la verdad de las contradicciones urbanas. La atenta y reflexiva visión de la representación fotográfica se convierte entonces en puro paisaje.

\subsubsection{Fuera}

La ciudad de cemento gris que ambos retratan genera las mismas estructuras a lo largo del mundo, tanto para los que están dentro de ellas, como para los que están fuera.

En estas dos fotos de Gabriele Basilico y Jeff Wall podemos sentir un color, aunque no lo veamos, del blanco y negro de las imágenes se desprende un ligero azulado que nos da sensación de frío. Podemos sentir el frío de la noche que retratan, no estamos en una terraza al fresco, sino en un frío incómodo, un frío de invierno. La temperatura que destilan nos sitúa fuera de casa en un entorno agresivo que no nos cuida, estamos desamparados. En la desarropada noche de invierno, podemos situarnos en dos territorios distintos: en el interior, en el calor del hogar, o en el exterior, en la fría noche. Ambos fotógrafos nos sitúan fuera y frente a estos dos territorios posibles, frente al calor o al frío.

Gabriele Basilico en su fotografía Milano nos coloca frente al interior ocupado por el calor, nosotros estamos fuera de ese refugio, sabemos que existe y no podemos acceder a él: primero hay un muro alto, después los bloques iguales y cerrados de una urbanización.

Jeff Wall en Night nos sitúa mirando el hogar de una vagabunda a la orilla del agua, frente al exterior ocupado en el frío. También estamos fuera de ese 'refugio' exterior y desde nuestra posición tampoco podemos acceder a él: delante de nosotros está el agua, como si del foso de un castillo se tratara.

Ambos nos sitúan ante dos posibles refugios en la noche para decirnos que estamos fuera, no podemos acceder a ninguno de los dos, estamos en la calle. Posicionándonos enfrente de los refugios posibles ambos fotógrafos nos hacen saber que desde esa posición estamos a la misma distancia de poder entrar en el calor o de quedarnos a vivir fuera en el frío. 
Pero la pregunta que nos hacen es retórica, no existe opción para la acción, estamos al otro lado del muro y el agua. No podemos pasar, somos meros espectadores, porque ni en uno ni en otro lado vamos a intervenir, es como si nos estuvieran reprochando nuestra actitud: ni lo ves ni lo sientes.

La posición del fotógrafo, y por lo tanto, la nuestra, la del receptor, sólo nos permite observar desde fuera, viendo cómo los otros generan su territorio por medio de paredes o recostándose sobre el suelo de la calle. Para nosotros el entorno es paisaje.

No se puede intervenir en lo que sucede: el muro y el agua impiden acceder al otro lado. El actor ignora nuestra presencia y nosotros le observamos como un voyeur oculto, a través de la cuarta pared del escenario. Los que viven en la escena están más allá de nuestro contexto y su relación con el entorno es completamente distinta, ellos generan su lugar, poseen el entorno que nosotros observamos. Nosotros poseemos el entorno desde la distancia de la vista que genera paisaje. El/La que se acomoda genera 'lugar' al asentarse en él.

En la fotografía Milano de Basilico existen dos territorios diferenciados a uno y otro lado del muro: a un lado el lugar propio, el territorio privado; al otro el lugar común, el territorio social gubernamental, el espacio público. Lo que observamos es el hogar, la casa, el lugar propio y privado habitual, donde descansar, guarecernos y cultivar nuestras relaciones más personales.

En la fotografía Night de Wall el territorio común, aquel que se rige por las normas del espacio público, ha sido ocupado por medio de una acción anormal, es decir, una acción fuera de los estándares socioculturales aceptados. Lo que vemos en esta foto de Jeff Wall es una mujer tumbada en el suelo y rodeada de cosas. Es la misma posición que adquiere la persona que está en el interior, detrás de la pared del edificio que retrata Basilico, pero la vagabunda de Wall realiza una acción no habitual en el entorno porque estamos en el espacio público, y tumbada en el suelo genera un entorno propio, un lugar ocupado, un hogar. La transformación es tan grande que genera un lugar privado, un hogar en el espacio público. 
La figura recurrente de la persona tendida en el suelo es una idea de espacio que introduce el contacto con el suelo. Este contacto transforma la relación con el paisaje como género pictórico sobre el territorio, en el paisaje, la idea de "vista" mantiene una distancia, sin embargo, la acción, el contacto, puede llegar a "excavar" el espacio, en particular en primer término (Chevrier, 2007, p. 342).

La relación de distancia que establece el paisaje o la relación sociocultural que se da en el espacio público se rompe porque la persona se encuentra tumbada en el suelo y su relación con el entorno varía, lo ocupa de tal manera que consigue "excavar el espacio" hasta lograr apropiárselo.

Los observados en la fotografía de Gabriele Basilico pueden encontrarse también tumbados, pero en sus camas, refugiados dentro de sus casas, detrás del muro. El paisaje no existe para ellos tampoco más allá de las imágenes que posean en el interior de su refugio.

Estamos en la calle, sin intervenir en lo que pasa, al otro lado del refugio, cálido o frío, en el paisaje viendo la vida de los demás, sus miserias y sus trascendencias como si fueran un espejo.

¿Por qué los fotógrafos nos colocan en el puro paisaje? El paisaje es distancia y vista interiorizada y ellos nos colocan delante de lo que no solemos ver. Nos proponen interiorizar, en la soledad de la mirada que piensa el mundo que le rodea, ese entorno frío, inhóspito, oscuro, negro... Quieren hacernos conscientes y partícipes de la violencia de la calle, aquella que, con ser más antigua y más continua, no parece preocupar a nadie (Berger, 2006, p. 99): no mires para otro lado, éste también es tu paisaje. No miramos, para no hacerlas conscientes y reales: la delgada línea que nos separa de estar en uno o en otro lado puede hacerse tangible.

El flaneur, el paseante actual, como afirma el propio Wall (2003), vive en un entorno fragmentado. Genera su identidad con respecto a pedazos de entorno, de su barrio al centro de su ciudad, del lugar en el que vive al lugar en el que trabaja, del imaginario colectivo de su ciudad al simbólico de su región o país, pero obviando los lugares intermedios que acechan entre ambos. Puede que cerca de su casa, ahí al lado, la negrura no le permita ver el 
entorno cercano que le rodea, pero eso no lo hará menos real o menos tangible, seguirá estando allí en la oscuridad de la noche.

\section{Negro, conclusiones}

Volvamos a las preguntas que nos hacíamos al principio: ¿por qué los fotógrafos quieren que nos fijemos en ese momento en ese lugar y de esa manera?

Estamos en un entorno en el que 'aparentemente' no pasa nada, en el que no hay proyecto, ni desarrollo, ni poder, es un entorno oculto. Pero, aunque estemos ante la oscuridad, si permanecemos el tiempo suficiente delante de la imagen y nos fijamos con atención, a pesar de que aparentemente no pase nada, podremos ver la acción posible que propone la fotografía artística contemporánea, una acción de resistencia a la norma: una acción marginal, imputable y repudiable por las normas, escritas o no, de la sociedad que la acoge.

La acción por antonomasia que genera lugar y permite apropiarse del entorno es yacer en él: tumbarse en un punto concreto. Si una persona se tumba en el espacio público se apropiará de él de tal manera que éste no podrá ser ocupado por ninguna otra, como podemos ver en la imagen Night. Entonces, el entorno en el que 'aparentemente' no pasaba nada se convierte en la alternativa al proyecto premeditado, al desarrollo, al poder... y desde esa acción consigue apoderarse de él. La legitimidad del acto no dirigido deviene de la necesidad de apropiarse de los recodos ante la privatización y el encorsetamiento que ha hecho del espacio público un entorno excluyente. Por medio de esa acción la identidad podrá surgir en un entorno no premeditadamente simbólico.

Además, la noche, el momento del día elegido por los fotógrafos, es una frontera temporal, es un territorio que posee sus propias normas y usos, un territorio con personalidad propia. El tiempo de la noche, es el tiempo del descanso, el silencio y el recogimiento; y al mismo tiempo el de las sombras, la tenebrosidad, la confusión y las tinieblas. 
Las fotografías Night y Milano poseen una parte de una negritud densa en el agua de abajo y en el cielo de arriba respectivamente. En Aral Station-1-40o y offen-open Tankstelle weiss - blau no existe nada más allá del sándwich de luz azulada que nos protege y asienta que el negro. El negro en realidad no es un color, es falta de luz. Según la teoría del color el negro es la ausencia de luz, es lo que se ve en la oscuridad. La clave baja de las imágenes y el momento del día elegido: la noche... nos colocan en un contexto de oscuridad formal (negro), inteligible (estamos fuera de casa y fuera del escenario) y sensible (solos en la noche fría). En todas las imágenes esa oscuridad se comporta como un agujero negro que contiene y absorbe toda la energía, porque posee toda la profundidad de lo invisible.

La fotografía artística contemporánea re-dibuja el paisaje con su mirada porque se adapta a él. Esta maniobra lleva al límite su propia esencia y a través de ella descubre la paradoja del paisaje.

La fotografía se metamorfosea con la esencia del entorno que representa y descubre la sustancia de la que está hecho: juega con la luz y la oscuridad para enseñarnos cómo nos deslumbran las imágenes del mundo o cómo se nos ocultan las alternativas.

En el momento en el que la foto plasma lo que no se ve, lo oculto, lo oscuro... es cuando se convierte en una imagen 'verdadera de la realidad', cuando ha llevado al límite su esencia. Es la paradoja de la fotografía: que se construye a través de la luz y se hace real en la oscuridad.

Es al mismo tiempo una necesidad intrínseca a la ontología de la imagen-foto artística. Cuando es imagen oscuridad, que representa el 'entorno oscuridad', nos habla del lugar posible y tangible, aunque oculto o invisible. Parece que en el momento de la toma, aquel que se refería al 'eso ha sido', al índice (cuando la luz pasa al plano focal), momento de oscuridad que oculta la imagen al fotógrafo, se forma la relación directa con la verdad de lo que representa.

Es la paradoja y la poética de la foto, y desde ese límite, desde ese umbral de su ser la oscuridad, nos descubre además la paradoja del paisaje: para 
generar lugar, para poder apropiarnos del espacio público, la fotografía propone la acción cercana, directa: propone romper con la distancia ontológica del paisaje, ocuparlo nos coloca en el escenario, nos convierte en sus actores.

\section{Referencias bibliográficas}

Ahrens, C. (2001). Many Many Colored Smarties or The Colors of a OneDimensional World. En Menzel, K. \& Ulm, S. Nightscapes: Fotografien der Nacht.

Augé, M. (1998). Los No Lugares. Espacios del Anonimato. Una Antropología de la Sobremodernidad. Barcelona: Gedisa.

Bachelard, G. (2004). La poética del espacio. Madrid: Fondo de Cultura Económica.

Bauman, Z. (1999). La Globalización: Consecuencias Humanas. Madrid: Fondo de Cultura Económica.

Berger, J. (2006). Ralph Fasanella y la ciudad. Mirar. Barcelona: Gustavo Gili.

Berroeta Torres, H., \& Vidal Moranta, T. (2012). La noción de espacio público y la configuración de la ciudad: fundamentos para los relatos de pérdida, civilidad y disputa. Polis. Revista Latinoamericana, (31). https://journals.openedition.org/polis/3612

Borja, J. (2000). Ciudad y ciudadanía. Dos notas. WP núm. 177. Barcelona: Institut de Ciències Polítiques i Socials.

Castells, M. (1998). El espacio de los flujos. La sociedad red en Vol. I de La era de la información: economía, sociedad y cultura. Madrid: Taurus.

Castells, M. (2001). La sociología urbana. Madrid: Alianza Editorial.

Chevrier, J-F. (2007). La fotografia entre las bellas artes y los medios de comunicación. Barcelona: Gustavo Gili.

Esparza, R. (2002). Salamanca, Un Proyecto Fotográfico. Salamanca: Consorcio Salamanca.

Fernández-Cid, M. (2008). Gabriele Basilico. La ciudad está llena de contradicciones que la fotografía separa y aísla. El Cultural, 4 de septiembre.

Francastel, P. (1988). La figura y el lugar. El orden visual del Quattrocento, Barcelona: Laia.

García Márquez, G. (2003). Vivir para contarla. Barcelona: Mondadori.

González-Valerio, B. G. (2018). La fotografía documental y la utopía. Miguel Hernández Communication Journal, (9), pp. 293-307. 
http://rev.innovacionumh.es/index.php?journal=mhcj\&page=article \&op=view\&path\%5B $\% 5 \mathrm{D}=251$

Gorelik, A. (2008). El romance del espacio público. Alteridades, 18 (36), pp. 8-15.

Hall, E. T. (1972) La dimensión oculta. México: Siglo XXI.

Pastor Andrés, G. (2016). Frenético, el espacio-tiempo en la fotografía artística contemporánea. Fotocinema: revista científica de cine y fotografía, (12), p. $103-129 . \quad$ DOI: http://dx.doi.org/10.24310/Fotocinema.2016.voi12.6038

Sennett, R. (1994). Carne y piedra. El cuerpo y la ciudad en la civilización occidental. Madrid: Alianza.

Boddy, T. (2004). New Urbanism: 'The Vancouver Model' (Speaking of Places). Places, vol. 16, núm. 2, p. 14. En: http://escholarship.org/uc/item/onsgfobo [Consulta: 20/07/2014].

Vidal Moranta, T. y Pol Urrutia, P. (2005). La apropiación del espacio: una propuesta teórica para comprender la vinculación entre las personas y los lugares. Anuario de Psicología. vol. 36, no 3, pp. 281-297. Barcelona: Facultat de Psicología. Universitat de Barcelona.

Wall, J. (2003). Jeff Wall. Ensayos y entrevistas. Salamanca: Centro de Arte de Salamanca.

Zielony, T. (2005). Post-it city. Ciudades ocasionales. En M. Peran y Barcelona: Centre de Cultura Contamporània de Barcelona, pp. 177179. 